\title{
Elevated lipid levels in patients with achilles tendon ruptures: a retrospective matching study
}

\author{
Yu-Ping Yang ${ }^{1 \#}$, Li-Yuan Tao ${ }^{2 \#}$, Jia-Ning Gao $^{3 \#}$, Peng Wang ${ }^{4}$, Yan-Fang Jiang ${ }^{1}$, Le-Min Zheng ${ }^{3}$, Yi-Ming \\ Zhao', Ying-Fang Ao ${ }^{1}$ \\ ${ }^{1}$ Institute of Sports Medicine, Peking University Third Hospital, Beijing Key Laboratory of Sports Injuries, Beijing 100191, China; ${ }^{2}$ Research \\ Center of Clinical Epidemiology, Peking University Third Hospital, Beijing 100191, China; ${ }^{3}$ The Institute of Cardiovascular Sciences and Institute \\ of Systems Biomedicine, School of Basic Medical Sciences, Key Laboratory of Molecular Cardiovascular Sciences of Ministry of Education, Peking \\ University Health Science Center, Beijing 100191, China; ${ }^{4}$ Physical Examination Center, Peking University Third Hospital, Beijing 100191 , China \\ Contributions: (I) Conception and design: YP Yang, LY Tao, JN Gao; (II) Administrative support: None; (III) Provision of study materials or patients: \\ None; (IV) Collection and assembly of data: YP Yang, P Wang, LY Tao, JN Gao; (V) Data analysis and interpretation: YP Yang, LY Tao, JN Gao; (VI) \\ Manuscript writing: All authors; (VII) Final approval of manuscript: All authors. \\ \#These authors contributed equally to this work. \\ Correspondence to: Ying-Fang Ao. Institute of Sports Medicine, Peking University Third Hospital, Beijing Key Laboratory of Sports Injuries, Beijing \\ 100191, China. Email: yingfang.ao@vip.sina.com; Yi-Ming Zhao. Research Center of Clinical Epidemiology, Peking University Third Hospital, \\ Beijing 100191, China. Email: yimingzhao115@163.com; Le-Min Zheng. The Institute of Cardiovascular Sciences and Institute of Systems \\ Biomedicine, School of Basic Medical Sciences, Key Laboratory of Molecular Cardiovascular Sciences of Ministry of Education, Peking University \\ Health Science Center, Beijing 100191, China. Email: zhengl@bjmu.edu.cn.
}

Background: Achilles tendon rupture (ATR) can lead to significant disability of patients. However, whether serum lipid levels are associated with ATR is still unclear. This study aimed to examine the difference in lipid levels between patients with and those without ATR.

Methods: Patients who received ATR surgery during January 2017 to December 2017 were categorized into the case group, and those who had physical examinations during the same period without ATR were in the control group. Different matching methods [case-control matching (CCM) and propensity score matching (PSM)] were used to match the cases and controls at a 1:1 ratio.

Results: Among a total of 216 pairs of subjects with CCM, cholesterol, triglyceride, and low-density lipoprotein $(\mathrm{LDL})$ levels were significantly higher $($ all $\mathrm{P}<0.05)$ in the case group than in the control group. Among 241 pairs of subjects with PSM, the same results as those with CCM were obtained. Abnormal rates of cholesterol, triglyceride, and LDL levels in the case group were also significantly higher than those in the control group in CCM and PSM (all $\mathrm{P}<0.05$ ). After adjusting for the factors of height and weight, there were still significant differences in cholesterol, triglyceride, and LDL levels, as well as high-density lipoprotein levels, between the case and control groups (all $\mathrm{P}<0.05$ ).

Conclusions: Cholesterol, triglyceride, and LDL levels in patients with ATR are higher than those in healthy people. Further studies are required to verify the effect of some components of lipids on Achilles tendon structure.

Keywords: Lipid; cholesterol; low-density lipoprotein; achilles tendon rupture (ATR); propensity score matching

Submitted Oct 05, 2019. Accepted for publication Dec 17, 2019.

doi: $10.21037 /$ atm.2020.01.11

View this article at: http://dx.doi.org/10.21037/atm.2020.01.11 


\section{Introduction}

Achilles tendon rupture (ATR) is a common clinical sports injury to the ankle function of patients. Some patients suffer from chronic ATR because of misdiagnosis. Many patients who have received an operation or are treated conservatively in time may not have satisfactory results, and live with pain and disability after treatment. Some functional deficits can last for longer than 10 years or even accompany patients for life $(1,2)$. The reported incidence rate of ATR varies from 11-37/100,000 in European countries (3-6). Closed ATR usually occurs in sports injuries. When the knee joint is straightened, the weight-bearing forefoot often kicks up, and the ankle is suddenly dorsiflexed or the forefoot touches the ground, causing severe dorsiflexion of the plantar-flexed foot. Direct violence or laceration on the contracted Achilles tendon can also cause ATR.

The pathogenesis of ATR is affected by many factors, including sports injury, inflammatory reaction, genetic susceptibility, and aging (7-9). Obesity, hypertension, diabetes and steroid use are also related to Achilles tendon diseases (10). Ozgurtas et al.'s small-sample population study showed that ATR was related to high lipid concentrations (11). They showed that triglyceride, total cholesterol, very low-density lipoprotein cholesterol, and lowdensity lipoprotein cholesterol (LDL-C) levels in patients with ATR were higher than those in patients in the control group. A meta-analysis showed that structural changes of the Achilles tendon and Achilles tendon pain were related to high total cholesterol, triglyceride, and LDL-C levels and low high-density lipoprotein cholesterol (HDL-C) levels (12). Additionally, Wang et al. showed that Achilles tendon thickness was positively correlated with LDL-C levels (13). To confirm lipid levels as a definite risk factor of ATR, a study with a larger number of patients comparing lipid levels between ruptured Achilles tendons and undamaged Achilles tendons is required.

Therefore, this study aimed to investigate the relationship between ATR and lipid levels in a larger population. Because ATR and lipid levels are affected by different factors, this study strictly selected subjects to remove the possible influence of relevant confounding factors as much as possible. Additionally, we adopted two forms of matching, casecontrol matching (CCM) and propensity score matching (PSM), to ensure that the study was appropriately powered.

\section{Methods}

\section{Subjects and data}

We retrospectively analyzed 287 patients who underwent
ATR repair surgery in the Institute of Sports Medicine, Peking University Third Hospital during January 2017 to December 2017. There were no athletes in this study. Among the above-mentioned patients, we excluded 25 because of a lack of data of lipids or other indicators, 6 professional athletes, 8 with hypertension, and 5 with diabetes. The remaining 243 patients were selected as the case group. A total of 10,375 people who underwent a physical examination at the Physical Examination Center of Peking University Third Hospital during the same period were selected as the control group. A total of 9,193 subjects remained after excluding those with no lipid test results, professional athletes, and those with hypertension or diabetes. These subjects were included in the control group for this study. The study was approved by the ethics committee of Peking University Third Hospital and the subjects were exempted from signing an informed consent form. General data, as well as data on blood glucose levels, lipid levels, blood uric acid levels, smoking, and drinking of the subjects were collected through the hospital information system.

We divided lipids into different groups according to the standard of the lipid test kit (Kanto Chemical co., ltd., Japan) that is used in Peking University Third Hospital. Total cholesterol levels $>6 \mathrm{mmol} / \mathrm{L}$, triglyceride levels $>1.8 \mathrm{mmol} / \mathrm{L}$, HDL levels $<0.78 \mathrm{mmol} / \mathrm{L}$, LDL levels $>3.62 \mathrm{mmol} / \mathrm{L}$, and uric acid levels $>420 \mu \mathrm{mol} / \mathrm{L}$ were defined as abnormal.

\section{Matching methods of subjects}

Matching ensures that the distributions of confounding variables are identical (or as close to identical as possible) so that the case group is comparable with the control group (14). CCM involves selecting a subject in the control group as the case-matched control who is completely consistent with the case according to the matching factors. However, in PSM, selection of a control for each case is based on the propensity score, not matching factors (15). To balance the baseline characteristics between groups, we used CCM and PSM to match patients with ATR and healthy people at a 1:1 ratio. The matching parameters included age, sex, body mass index (BMI), and blood glucose levels. In CCM, the maximum allowance of difference (MAD) of age was set to 1 year old, the MAD of a BMI was $0.5 \mathrm{~kg} / \mathrm{m}^{2}$, the $\mathrm{MAD}$ of plasma glucose levels was $0.5 \mathrm{mmol} / \mathrm{L}$ and an exact match was used for sex. A total of 216 pairs of subjects were matched (Figure 1). In PSM, the matching tolerance score between the case group and the control group was set at 0.001 . 


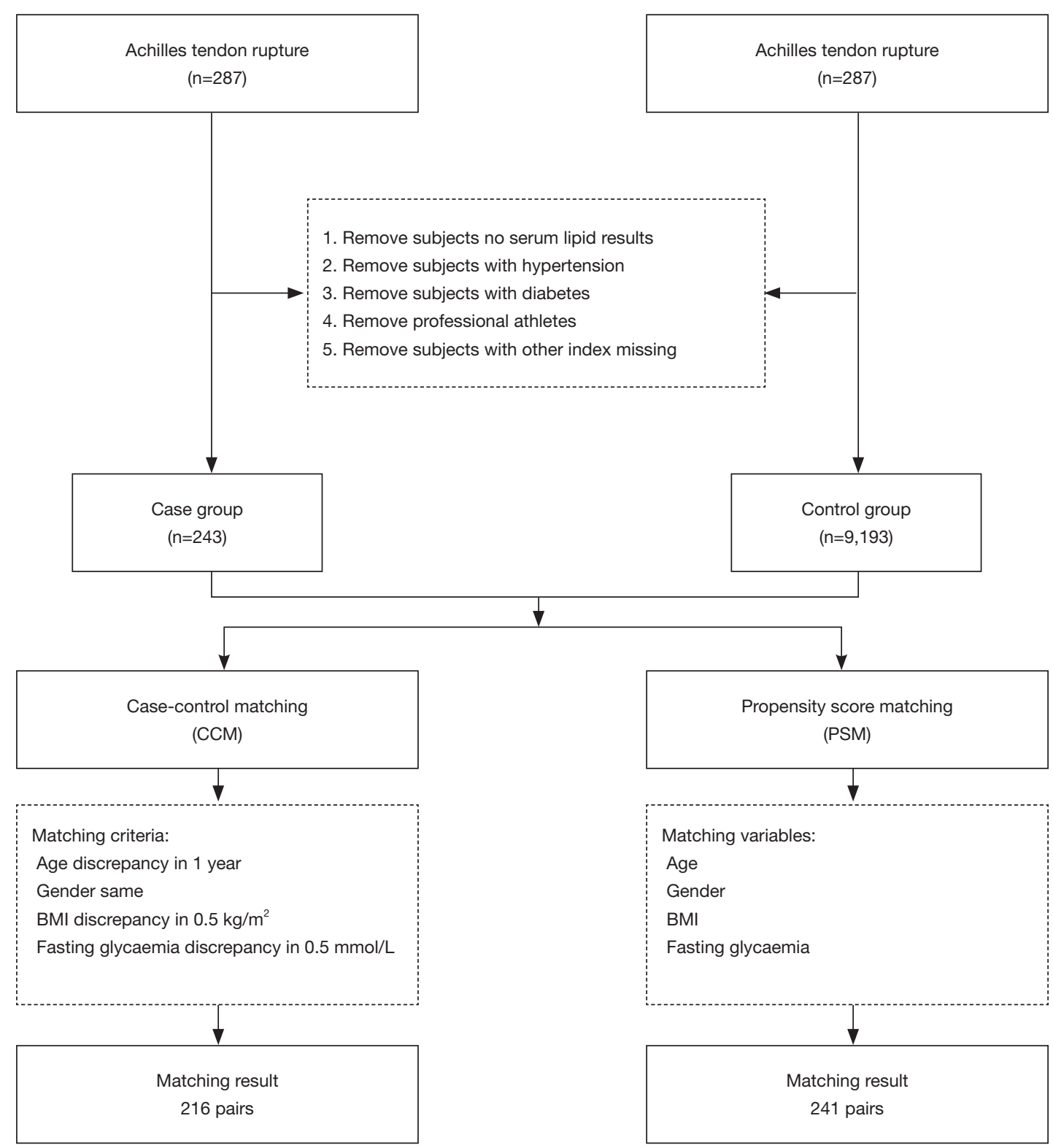

Figure 1 Flow chart of the subject selection and matching.

A total of 241 pairs of subjects were matched (Figure 1).

\section{Statistical analysis}

We used the R software (Version 3.1.1) "MatchIt" package for PSM and SPSS 25.0 for CCM for statistical analysis (16). We used the Kolmogorov-Smirnov test for determining normality of continuous data. Continuous data that had a normal distribution are expressed as mean \pm standard deviation and the independent sample t-test was used for comparison between groups. Continuous data that were not normally distributed are expressed as the median $\left(25^{\text {th }}\right.$ and $75^{\text {th }}$ percentiles), and we used the Mann-Whitney $U$ test for comparison between groups.

To control for the effect of the patients' height and weight on lipid levels, the generalized linear model was used. All tests were two-sided and $\mathrm{P}<0.05$ was considered statistically significant. 
Table 1 Comparison of baseline characteristics between the two groups

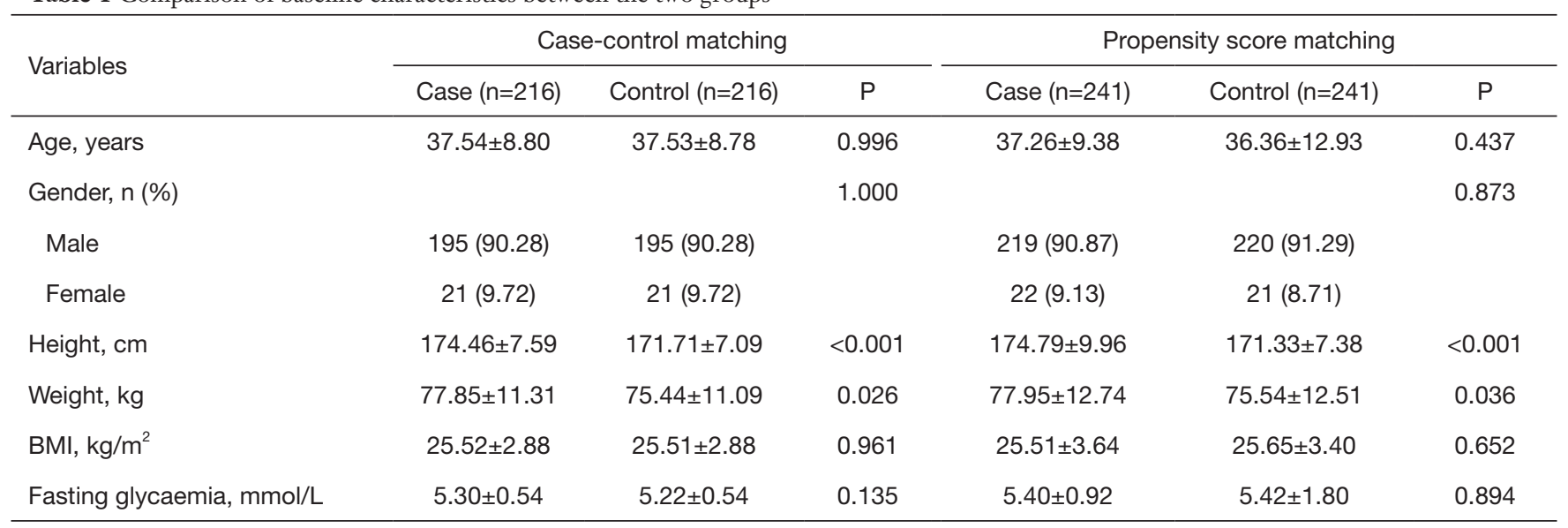

The case group is achilles tendon rupture (ATR) patients; the control group is the healthy controls.

Table 2 Differences of uric acid and plasma lipid between the two groups

\begin{tabular}{|c|c|c|c|c|c|c|}
\hline Variables & \multicolumn{3}{|c|}{ Case-control matching } & \multicolumn{3}{|c|}{ Propensity score matching } \\
\hline Cholesterol, $\mathrm{mmol} / \mathrm{L}$ & $3.74(3.41-4.19)$ & $4.77(4.14-5.40)$ & $<0.001$ & $3.37(3.09-3.59)$ & $4.77(4.14-5.36)$ & $<0.001$ \\
\hline Triglyceride, $\mathrm{mmol} / \mathrm{L}$ & $1.18(0.84-1.72)$ & $1.55(1.06-2.25)$ & $<0.001$ & $0.98(0.73-1.37)$ & $1.51(1.06-2.17)$ & $<0.001$ \\
\hline $\mathrm{HDL}, \mathrm{mmol} / \mathrm{L}$ & $1.07(0.96-1.25)$ & $1.09(0.98-1.31)$ & 0.143 & $1.08(0.96-1.26)$ & $1.09(0.98-1.31)$ & 0.252 \\
\hline
\end{tabular}

Data were expressed as median $\left(25^{\text {th }}-75^{\text {th }}\right.$ percentile) and tested by the Mann-Whitney $U$ test.

\section{Results}

\section{Characteristics of the subjects}

Age, sex, BMI, and blood glucose levels were not significantly different between the case and control groups in the two matching approaches. However, height was slightly higher (approximately $3 \mathrm{~cm}$ ) and weight was slightly heavier (approximately $2.4 \mathrm{~kg}$ ) in patients in the case group than in subjects in the control group (both $\mathrm{P}<0.05)$ (Table 1).

\section{Comparison of lipid levels between the case group and the control group}

Among the 216 matched pairs of subjects, median cholesterol, triglyceride, and LDL levels in the case group were significantly higher than those in the control group (all $\mathrm{P}<0.001$ ) (Table 2 and Figure 2). The same results were also found in the 241 pairs of subjects matched with PSM (Table 2 and Figure 3).
The subjects were then divided into healthy and abnormal groups by their test values according to the standard of the serum lipid kit. In CCM, the rates of patients with abnormal cholesterol, triglyceride, and LDL levels in the case group were significantly higher than those in the control group (all $\mathrm{P}<0.01)$. The same phenomenon was found in PSM (Table 3).

\section{Multivariate analysis of differences in lipid levels between the case and control groups}

In CCM and PSM, patients in the case group were slightly taller and heavier than those in the control group, but there was no significant difference in BMI between the groups. To remove the influence of height and weight on lipids, the generalized linear model was used to examine the effect of lipids between groups. We found that the case group had significantly higher cholesterol, triglyceride, HDL, and LDL levels than did the control group (all $\mathrm{P}<0.05$, Table 4). 


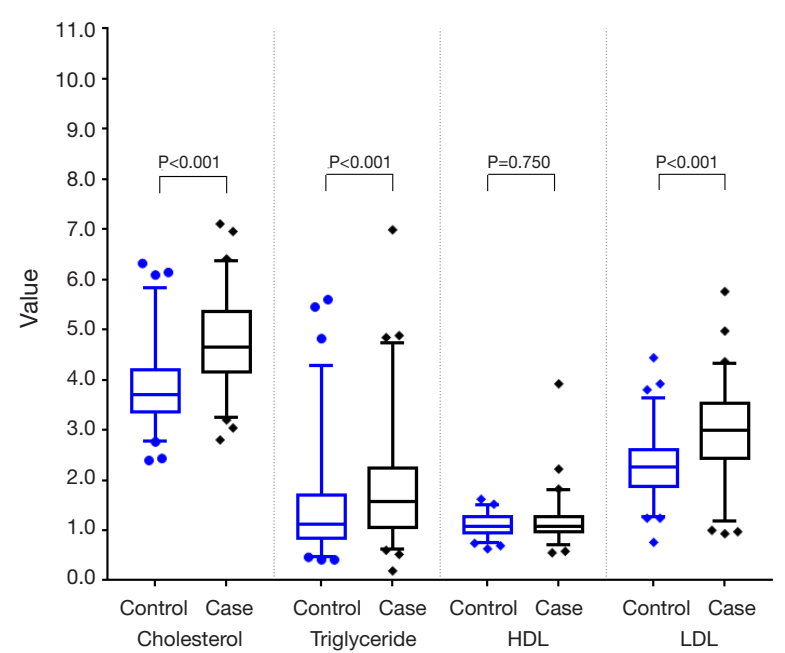

Figure 2 Comparison of plasma lipid between the two groups in case-control matching.

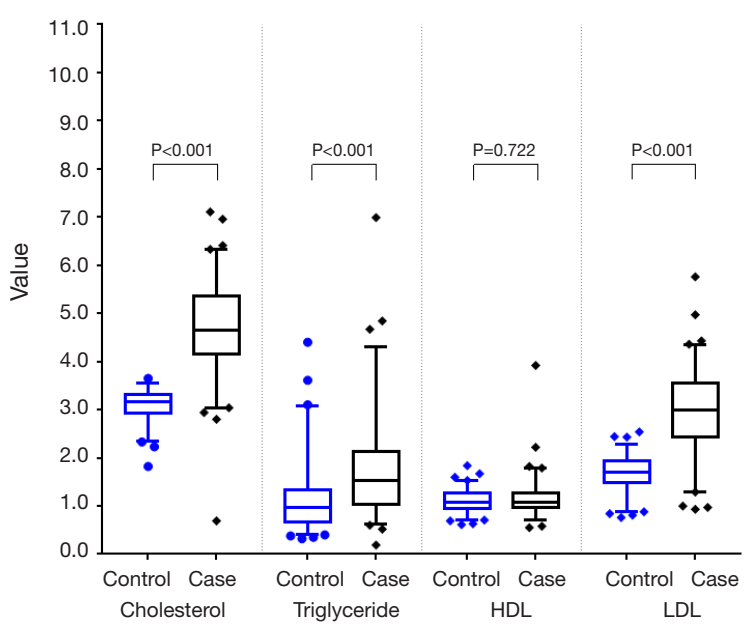

Figure 3 Comparison of plasma lipid between the two groups in propensity score matching.

\section{Discussion}

This study aimed to examine whether high lipid levels are an essential factor of ATR by a retrospective matching study. We found that although patients with ATR were taller and heavier than controls, there was no significant difference in age, sex, BMI, and fasting blood glucose levels between the groups. Furthermore, cholesterol, triglyceride, and LDL levels in patients with ATR were significantly higher than those in controls, which is consistent with the results of Ozgurtas et al. (11) and Tilley et al. (12).

The Achilles tendon is connective tissue and is mainly composed of the extracellular matrix. The Achilles tendon comprises a large amount of vertically arranged type I collagen, a small amount of types III and V collagen, and proteoglycan, and it is the strongest and largest tendon in the human body $(17,18)$. ATR is a common injury. In recent years, the incidence of ATR has increased, and this phenomenon is more evident with aging of the population $(5,6)$. There are many causes of ATR. Previous studies have reported pathological changes in tendons in patients with hypercholesterolemia (19) and elevated cholesterol levels in patients with ATR $(11,20)$. A meta-analysis also showed that, in patients with changes in tendon structure or tendon pain, total cholesterol, LDL cholesterol, and triglyceride levels were significantly elevated, and that HDL cholesterol levels were reduced (12). However, there have been no large-sample studies on whether lipid levels of patients with ATR are significantly higher than those in healthy people. We studied 287 patients with ATR and matched them on the basis of necessary matching parameters with 10,375 healthy people. Under different matching conditions, we found that cholesterol, triglyceride, and LDL levels in patients with ATR were higher than those in healthy people. A hypothesis has been proposed that greater weight, which exerts external force on the tendon, and tension, which is induced by muscular contraction, are possible causes of ATR (21). To remove the influence of height and weight on lipid levels, we used the generalized linear model in this study. The generalized linear model is a derivative of the linear model under non-normal distribution, and it is a type of multifactor analysis, which can adjust for the effect of other variables. After adjusting for the effects of height and weight, we found that patients in the case group had significantly higher cholesterol, triglyceride, HDL, and LDL levels than did the control group. This finding suggests that lipid levels in patients with ATR are abnormal.

We speculate that free cholesterol and triglycerides accumulate in the Achilles tendon of patients with ATR because they often have high serum lipid levels due to bad living habits, such as a high-fat diet and smoking. Such deposition can cause Achilles tendon xanthomas, which may lead to rupture of the Achilles tendon and is also a sign of hyperlipidemia. The incidence of Achilles tendon xanthomas is relatively higher in patients with familial hypercholesterolemia than in other people (22-24). Statins and PCSK9 inhibitors inhibit the lipid deposition process (25-27). Whether the use of such drugs for patients with hyperlipemia can reduce lipid deposition in the Achilles tendon needs to be studied in the future. 
Table 3 Abnormal rate in uric acid and plasma lipid of the two groups

\begin{tabular}{|c|c|c|c|c|c|c|}
\hline Variables & \multicolumn{3}{|c|}{ Case-control matching, n (\%) } & \multicolumn{3}{|c|}{ Propensity score matching, $\mathrm{n}(\%)$} \\
\hline Cholesterol, $\mathrm{mmol} / \mathrm{L}$ & $3(1.39)$ & $21(9.72)$ & $<0.001$ & $3(1.24)$ & $24(9.96)$ & $<0.001$ \\
\hline Triglyceride, $\mathrm{mmol} / \mathrm{L}$ & $49(22.69)$ & $78(36.11)$ & 0.002 & $27(11.2)$ & $86(35.68)$ & $<0.001$ \\
\hline $\mathrm{HDL}, \mathrm{mmol} / \mathrm{L}$ & $5(2.31)$ & $8(3.70)$ & 0.398 & $13(5.39)$ & 8 (3.32) & 0.265 \\
\hline
\end{tabular}

Table 4 Results of the generalized linear model analysis

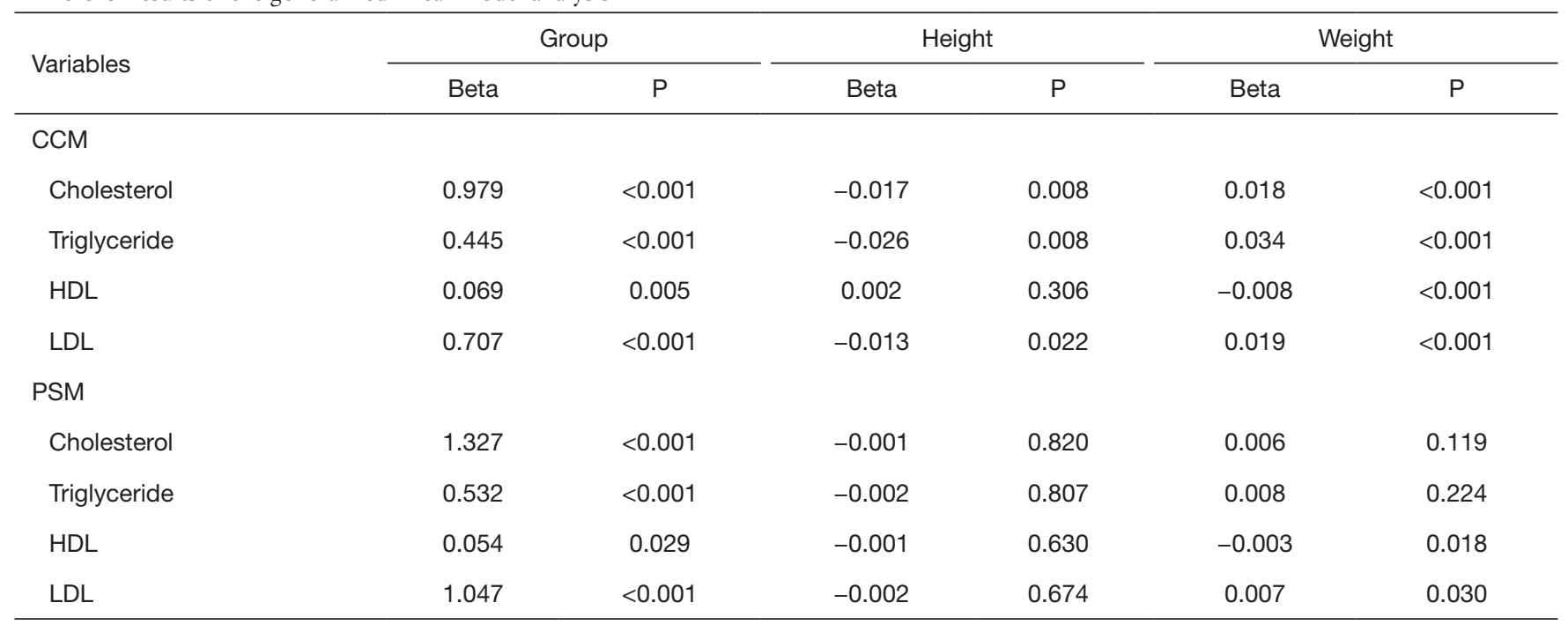

CCM, case-control matching; PSM, propensity score matching.

ATR is related to its mechanical structure. A total of $70 \%$ of the dry weight of the Achilles tendon is collagen, of which there is $95 \%$ type I collagen $(28,29)$. Assembly of type I collagen into fibrils was originally believed to be a spontaneous and entropy-driven process. However, a recent study showed that collagen fibril formation is under close cellular control and is dynamically integrated with fibronectin assembly (30). Moreover, vascular smooth muscle cells with lipid deposition (i.e., smooth muscle foam cells) leads to abnormal collagen polymerization, reducing the assembly ability of cell collagen fibers. This further reduces the strength of the Achilles tendon (31,32). Hypercholesterolemia may lead to an increase in matrix metalloproteinase activity and breakdown of collagen. Subsequently, this leads to fragility and ATR (33).

Cholesterol is not only deposited in the extracellular matrix, but also accumulates in cells, such as macrophages and other immune cells. This process promotes inflammatory reactions, including increasing Tolllike receptor signaling, inflammasome activation, and production of monocytes and neutrophils in the bone marrow and spleen. At the cellular level, activation of Tolllike receptor signaling leads to decreased cholesterol efflux, which leads to further accumulation of cholesterol and amplification of the inflammatory response (34). Tissues of patients with tendon diseases and ATR show chronic inflammation (9). Inflammation can lead to the occurrence and development of tendon diseases. Inflammatory infiltration may trigger the release of oxygen free radicals, protease, and other factors that damage cells. The Fas system is also activated and this leads to cellular apoptosis, causing degeneration of the Achilles tendon, and eventually rupture occurs $(8,35,36)$. Accumulation of foam cells, which contain a large amount of oxidized LDL, may also be involved in this process (34). In this process, a newly discovered mechanism may be involved (37). A type of 
phospholipid bilayer membrane-enclosed vesicle, called an extracellular vesicle, can be released by inflammatoryrelated cells, including platelets, leukocytes, monocytes, macrophages, and other cells. Extracellular vesicles play roles in biological and pathological processes (38-40). Extracellular vesicles may also intensify the communication of inflammatory factors from macrophages to tendons (41). At the site of the Achilles tendon tissue where lipids are accumulated, the load-bearing capacity is poorer, and the tissue is loose and more fragile than in normal tendon tissue. The tendon tissue is infiltrated by inflammatory factors, which eventually leads to ATR. However, this speculation requires further pathological staining of lipids for further verification.

Hyperlipidemia leads to hypercoagulation of plasma and atherosclerosis, which promote thrombosis (42). Small thrombosis, occlusive arterial disease, and decreased blood flow disturb the microvasculature of the tendon and result in insufficiency in the local blood circulation. Poor circulation may result in local tissue hypoxia, and impaired nutrition and energy metabolism. Taken together, these factors are likely to play an essential role in the sequence of events that lead to degeneration of tendons $(10,43)$.

In this study, we did not collect data on smoking or diet of patients, which may have led to confounding factors. In future studies, we will obtain more lifestyle information of patients and conduct tissue biopsies of tendon tissues to determine the status of lipid accumulation.

In conclusion, cholesterol, triglyceride, and LDL levels in patients with ATR are higher than those in healthy people, and this may be caused by deposition of lipids at the Achilles tendon. A prospective cohort study should be carried out to confirm our findings. Lipoprotein and key proteins, such as matrix metalloproteinase, should be stained in collected Achilles tendon samples, and the effect of some components of lipids on the structure of Achilles tendon should be further investigated.

\section{Acknowledgments}

Funding: This work was supported by the National Natural Science Foundation of China (91639108, 81970425 and 81770272).

\section{Footnote}

Conflicts of Interest: The authors have no conflicts of interest to declare.
Ethical Statement: The authors are accountable for all aspects of the work in ensuring that questions related to the accuracy or integrity of any part of the work are appropriately investigated and resolved. The study was performed in accordance with the standards of ethics outlined in the Declaration of Helsinki. All study procedures were reviewed by the Peking University Third Hospital Medical Science Research Ethics Committee.

Open Access Statement: This is an Open Access article distributed in accordance with the Creative Commons Attribution-NonCommercial-NoDerivs 4.0 International License (CC BY-NC-ND 4.0), which permits the noncommercial replication and distribution of the article with the strict proviso that no changes or edits are made and the original work is properly cited (including links to both the formal publication through the relevant DOI and the license). See: https://creativecommons.org/licenses/by-nc-nd/4.0/.

\section{References}

1. Castro M, Melão L, Canella C, et al. Lisfranc joint ligamentous complex: MRI with anatomic correlation in cadavers. AJR Am J Roentgenol 2010;195:W447-55.

2. Kujala UM, Sarna S, Kaprio J. Cumulative incidence of achilles tendon rupture and tendinopathy in male former elite athletes. Clin J Sport Med 2005;15:133-5.

3. Järvinen TA, Kannus P, Maffulli N, et al. Achilles tendon disorders: etiology and epidemiology. Foot Ankle Clin 2005;10:255-66.

4. Houshian S, Tscherning T, Riegels-Nielsen P. The epidemiology of Achilles tendon rupture in a Danish county. Injury 1998;29:651-4.

5. Lantto I, Heikkinen J, Flinkkila T, et al. Epidemiology of Achilles tendon ruptures: increasing incidence over a 33year period. Scand J Med Sci Sports 2015;25:e133-8.

6. Huttunen TT, Kannus P, Rolf C, et al. Acute achilles tendon ruptures: incidence of injury and surgery in Sweden between 2001 and 2012. Am J Sports Med 2011;121:16235.

7. Nell EM, van der Merwe L, Cook J, et al. The apoptosis pathway and the genetic predisposition to Achilles tendinopathy. J Orthop Res 2012;30:1719-24.

8. Dakin SG, Martinez FO, Yapp C, et al. Inflammation activation and resolution in human tendon disease. Sci Transl Med 2015;7:311ra173.

9. Dakin SG, Newton J, Martinez FO, et al. Chronic inflammation is a feature of Achilles tendinopathy and rupture. Br J Sports Med 2018;52:359-67. 
10. Holmes GB, Lin J. Etiologic factors associated with symptomatic achilles tendinopathy. Foot Ankle Int 2006;27:952-9.

11. Ozgurtas T, Yildiz C, Serdar M, et al. Is high concentration of serum lipids a risk factor for Achilles tendon rupture? Clin Chim Acta 2003;331:25-8.

12. Tilley BJ, Cook JL, Docking SI, et al. Is higher serum cholesterol associated with altered tendon structure or tendon pain? A systematic review. Br J Sports Med 2015;49:1504-9.

13. Wang B, Zhang Q, Lin L, et al. Association of Achilles tendon thickness and LDL-cholesterol levels in patients with hypercholesterolemia. Lipids Health Dis 2018;17:131.

14. Mansournia MA, Jewell NP, Greenland S. Case-control matching: effects, misconceptions, and recommendations. Eur J Epidemiol 2018;33:5-14.

15. Baek S, Park SH, Won E, et al. Propensity score matching: a conceptual review for radiology researchers. Korean J Radiol 2015;16:286-96.

16. Ho DE, Imai K, King G, et al. MatchIt: Nonparametric Preprocessing for Parametric Causal Inference. J Stat Softw 2011;42:16235.

17. Kauwe M. Acute Achilles Tendon Rupture. Clin Podiatr Med Surg 2017;34:229-43.

18. Svensson RB, Heinemeier KM, Couppe C, et al. Effect of aging and exercise on the tendon. J Appl Physiol (1985) 2016;121:1237-46.

19. Soslowsky LJ, Fryhofer GW. Tendon Homeostasis in Hypercholesterolemia. Adv Exp Med Biol 2016;920:151-65.

20. Mathiak G, Wening JV, Mathiak M, et al. Serum cholesterol is elevated in patients with Achilles tendon ruptures. Arch Orthop Trauma Surg 1999;119:280-4.

21. Gaida JE, Ashe MC, Bass SL, et al. Is adiposity an underrecognized risk factor for tendinopathy? A systematic review. Arthritis Rheum 2009;61:840-9.

22. Harada T, Inagaki-Tanimura $K, \operatorname{Nagao} M$, et al. Frequency of Achilles Tendon Xanthoma in Patients with Acute Coronary Syndrome. J Atheroscler Thromb 2017;24:949-53.

23. Vermeer BJ, Mateysen AA, van Gent CM, et al. The lipid composition and localization of free and esterified cholesterol in different types of xanthomas. J Invest Dermatol 1982;78:305-8.

24. Kajinami K, Nishitsuji M, Takeda Y, et al. Long-term probucol treatment results in regression of xanthomas, but in progression of coronary atherosclerosis in a heterozygous patient with familial hypercholesterolemia. Atherosclerosis 1996;120:181-7.
25. Bea AM, Perez-Calahorra S, Marco-Benedi V, et al. Effect of intensive LDL cholesterol lowering with PCSK9 monoclonal antibodies on tendon xanthoma regression in familial hypercholesterolemia. Atherosclerosis 2017;263:92-6.

26. Tsouli SG, Xydis V, Argyropoulou MI, et al. Regression of Achilles tendon thickness after statin treatment in patients with familial hypercholesterolemia: an ultrasonographic study. Atherosclerosis 2009;205:151-5.

27. Kaleağasıŏlu F, Olcay E, Olgac V. Statin-induced calcific Achilles tendinopathy in rats: comparison of biomechanical and histopathological effects of simvastatin, atorvastatin and rosuvastatin. Knee Surg Sports Traumatol Arthrosc 2017;25:1884-91.

28. Liu SH, Yang RS, Al-Shaikh R, et al. Collagen in tendon, ligament, and bone healing. A current review. Clin Orthop Relat Res 1995;(318):265-78.

29. Kjaer M. Role of extracellular matrix in adaptation of tendon and skeletal muscle to mechanical loading. Physiol Rev 2004;84:649-98.

30. Li S, Van Den Diepstraten C, D'Souza SJ, et al. Vascular smooth muscle cells orchestrate the assembly of type I collagen via 21 integrin, RhoA, and fibronectin polymerization. Am J Pathol 2003;163:1045-56.

31. Frontini MJ, O'Neil C, Sawyez C, et al. Lipid incorporation inhibits Src-dependent assembly of fibronectin and type I collagen by vascular smooth muscle cells. Circ Res 2009; 104:832-41.

32. Biancalana A, Veloso LA, Taboga SR, et al. Implications of obesity for tendon structure, ultrastructure and biochemistry: a study on Zucker rats. Micron 2012;43:463-9.

33. Rekhter MD, Hicks GW, Brammer DW, et al. Hypercholesterolemia causes mechanical weakening of rabbit atheroma: local collagen loss as a prerequisite of plaque rupture. Circ Res 2000;86:101-8.

34. Tall AR, Yvan-Charvet L. Cholesterol, inflammation and innate immunity. Nat Rev Immunol 2015;15:104-16.

35. Millar NL, Hueber AJ, Reilly JH, et al. Inflammation is present in early human tendinopathy. Am J Sports Med 2010;38:2085-91.

36. Dakin SG, Buckley CD, Al-Mossawi MH, et al. Persistent stromal fibroblast activation is present in chronic tendinopathy. Arthritis Res Ther 2017;19:16.

37. EL Andaloussi S, Mäger I, Breakefield XO, et al. Extracellular vesicles: biology and emerging therapeutic opportunities. Nat Rev Drug Discov 2013;12:347-57.

38. Taraboletti G, D'Ascenzo S, Borsotti P, et al. Shedding 
of the matrix metalloproteinases MMP-2, MMP-9, and MT1-MMP as membrane vesicle-associated components by endothelial cells. Am J Pathol 2002;160:673-80.

39. Helal O, Defoort C, Robert S, et al. Increased levels of microparticles originating from endothelial cells, platelets and erythrocytes in subjects with metabolic syndrome: relationship with oxidative stress. Nutr Metab Cardiovasc Dis 2011;21:665-71.

40. Sarlon-Bartoli G, Bennis Y, Lacroix R, et al. Plasmatic level of leukocyte-derived microparticles is associated with unstable plaque in asymptomatic patients with high-grade

Cite this article as: Yang YP, Tao LY, Gao JN, Wang P, Jiang YF, Zheng LM, Zhao YM, Ao YF. Elevated lipid levels in patients with achilles tendon ruptures: a retrospective matching study. Ann Transl Med 2020;8(5):217. doi: 10.21037/ atm.2020.01.11 carotid stenosis. J Am Coll Cardiol 2013;62:1436-41.

41. Niu C, Wang X, Zhao M, et al. Macrophage Foam CellDerived Extracellular Vesicles Promote Vascular Smooth Muscle Cell Migration and Adhesion. J Am Heart Assoc 2016;5:e004099.

42. Badimon L, Vilahur G. Thrombosis formation on atherosclerotic lesions and plaque rupture. J Intern Med 2014;276:618-32.

43. Järvinen M, Jozsa L, Kannus P, et al. Histopathological findings in chronic tendon disorders. Scand J Med Sci Sports 1997;7:86-95. 